\title{
Sistem Pakar Untuk Mengidentifikasi Permasalahan Siswa dan Menentukan Solusinya dengan Menggunakan Metode Naïe Bayes Classifier
}

\author{
Enita Try Saadyah (12018028) ${ }^{a, 1,}$, Sri Winiarti $(0516127501)^{b, 2}$ \\ ${ }^{a}$ Program Studi Teknik Informatika Universitas Ahmad Dahlan \\ J1. Prof. Dr.Soepomo, Janturan, Yogyakarta 55164, Indonesia \\ ${ }^{1}$ Email: trynita31@gmail.com; ${ }^{2}$ Email: sri.winiarti@tif.uad.ac.id
}

\begin{abstract}
ABSTRAK
Bimbingan konseling merupakan aspek yang penting dalam proses pembelajaran karena bimbingan konseling merupakan pemberian bantuan. Dimana "bantuan" disini tidak diartikan sebagai bantuan materil, melainkan bantuan yang bersifat menunjang bagi pengembangan pribadi bagi siswa yang dibimbing. Dalam konseling tidak dipungkiri adanya keterlambatan dalam pengambilan kesimpulan serta solusi yang tepat atas permasalahan yang dialami oleh siswa, untuk itu dibutuhkan sebuah aplikasi atau sistem pakar. Dalam melakukan konseling diperlukan sebuah sistem cerdas yang akan membantu guru bimbingan konseling dalam pengambilan keputusan serta dapat mengontrol siswa-siswi memiliki masalah sedini mungkin.
\end{abstract}

Subyek penelitian yang akan dibahas pada penelitian ini adalah "Sistem Pakar dalam Penentuan Solusi Bagi Siswa Dengan Menggunakan Metode Nä̈ve Bayes Classifier" yang diimplementasikan menggunakan bahasa pemrograman PHP dan MySQL. Pada penelitian ini menggunakan beberapa data, yaitu: data siswa, data fakta, data permasalahan dan data solusi. Selain menggunakan data yang telah disebutkan, penelitian ini juga membutuhkan desain sistem yang diantaranya meliputi membuat tabel aturan, kamus data, Diagram Alir Data (DAD) dan rancangan manajemen data yaitu Entity Relationship Diagram (ERD) dan desain relasional basisdata. Perancangan aplikasi ini dibuat menggunakan metode Naive Bayes Classifier dan mesin inferensi Forward Chaining. Metode pengumpulan data dengan menggunakan metode studi pustaka, wawancara dan observasi.

Dari penelitian yang dilakukan, menghasilkan sebuah sistem cerdas yang akan membantu guru bimbingan konseling dalam pengambilan keputusan konsultasi, membantu guru bimbingan konseling untuk mengontrol siswa-siswi dan mendokumentasikan pengetahuan seorang pakar yang dapat dijadikan sebagai media konsultasi. Hasil uji coba sistem dengan menggunakan Usability Testing dan User Acceptance Test (UAT), menunjukkan bahwa metode naive bayes classifier dapat diterapkan dalam bimbingan konseling dengan akurasi $100 \%$.

Ciptaan disebarluaskan di bawah lisensi CC-BY-SA.

Kata kunci: konseling, naive bayes classifier, sistem pakar.

\section{Pendahuluan}

Setiap sekolah perlu melakukan pembinaan kedisiplinan dan konseling bagi siswa guna untuk mencapai tujuan pendidikan yang diinginkan. Seiring dengan perkembangan zaman problematika peserta didik di sekolah semakin beragam. Jalan pikiran mereka menjadi terbagi dengan masalah di luar sekolah dan di dalam sekolah.

Bimbingan dan konseling adalah pelayanan bantuan untuk peserta didik, baik secara perorangan maupun kelompok agar mandiri dan bisa berkembang secara optimal, dalam bimbingan pribadi, sosial, belajar maupun karir melalui berbagai jenis layanan dan kegiatan pendukung berdasarkan norma-norma yang berlaku (SK Mendikbud No. 025/D/1995). 
Pendidikan tidak hanya belajar dan mencari ilmu formal yang ada di instansi-instansi pendidikan, tapi pendidikan adalah segala upaya manusia untuk merubah dirinya agar bisa menyesuaikan diri dengan lingkungannya.

Guru bimbingan konseling (BK) memiliki tugas untuk membimbing dan mengarahkan siswasiswi ketika siswa-siswinya menghadapi permasalahan-permasalahan yang membutuhkan pengarahan atau konsultasi. Dalam proses konseling tidak dipungkiri jika guru mengalami keterlambatan dan kesulitan dalam menentukan solusi yang tepat untuk mengatasi permasalahan yang sedang dialami oleh siswa. Selain itu, hukuman fisik seperti memukul, menjewer, mencubit kadang dilakukan untuk mendisiplinkan siswa ketika mereka dianggap telah melakukan suatu kesalahan yang seharusnya bisa diberikan solusi atas kesalahan yang telah dilakukan.

Pada penelitian ini disusun sistem pakar berbasis pengetahuan mengenai permasalahan serta solusi yang akan diberikan kepada siswa-siswi yang mengalami permasalahan di sekolah. Informasi yang diberikan ini berdasarkan pada fakta atau tanda yang dimasukkan oleh user yaitu guru bimbingan konseling. Sistem ini nanti akan menggunakan metode Naive Bayes Classifier dimana metode ini dapat menangani masalah sehingga akan ada nilai prediksi.

\section{Landasan Teori}

Penelitian sebelumnya yang dilakukan oleh Ridwan, dkk (2013) membahas tentang penerapan data mining untuk evaluasi kineja akademik mahasiswa menggunakan metode Naive bayes classifier. Hasil penelitian ini berupa klasifikasi kinerja akademik mahasiswa yang diprediksi kelulusannya dan memberikan rekomendasi untuk proses kelulusan tepat waktu atau lulus dalam waktu yang paling tepat dengan nilai optimal.

\subsection{Sistem Pakar}

Secara umum, sistem pakar (expert system) adalah sistem yang berusaha mengadopsi pengetahuan manusia ke komputer, agar komputer dapat menyelesaikan masalah seperti yang biasa dilakukan oleh para ahli. Sistem pakar yang baik dirancang agar dapat menyelesaikan suatu permasalahan tertentu dengan meniru kerja dari para ahli.

\subsection{Naive Bayes Classifier (NBC)}

Naive Bayes Classifier (NBC) merupakan teknik prediksi berbasis probabilistik sederhana yang berdasar pada penerapan teorema Bayes atau aturan Bayes dengan asumsi independensi (ketidaktergantungan) yang kuat (naif). Nä̈ve Bayes Classifier merupakan metode yang memanfaatkan perhitungan probabilitas yaitu memprediksi probabilitas dimasa depan berdasarkan pengalaman dimasa sebelumnya.

Formulasi Naive Bayes untuk klasifikasi adalah:

$$
P(Y \mid X)=\frac{P(Y) \pi_{i=1}^{d} P\left(X_{i} \mid Y\right)}{P(X)}
$$

Dimana:

a. $\mathrm{P}(\mathrm{Y} \mid \mathrm{X})$ adalah probabilitas data dengan vektor $\mathrm{X}$ pada kelas $\mathrm{Y}$.

b. $\mathrm{P}(\mathrm{Y})$ adalah probabilitas awal kelas $\mathrm{Y}$. $\frac{\pi_{i=1}^{d} P\left(X_{i} \mid Y\right)}{P(X)}$ adalah probabilitas independen kelas $\mathrm{Y}$ dari semua fitur dalam vektor $\mathrm{X}$.

Jika diimplementasikan kedalam sistem pakar untuk mengidentifikasi permasalahan siswa dan menentukan solusi, maka:

Dimana;

$$
P(M \mid X)=\frac{P(M) \cdot \text { nilai probabilitas }}{P(X)}
$$

a. Variabel $\mathrm{Y}=\mathrm{M}$ yaitu masalah.

b. Variabel $\mathrm{X}$ yaitu fakta yang diinputkan user. 
c. $\mathrm{P}(\mathrm{M} \mid \mathrm{X})=$ probabilitas fakta pada masalah

d. $P(X)=$ batas nilai ambang dari fakta yang ditentukan oleh pakar.

e. $\mathrm{P}(\mathrm{M})=$ batas nilai ambang dari masalah yang ditentukan oleh pakar.

Nilai probabilitas $=\frac{\text { jumlah siswa yang melakukan fakta }}{\text { jumlah total semua siswa }}$

\section{Metodologi}

\subsection{Metode Pengumpulan Data}

Dalam melakukan penelitian ini metode pengumpulan data yang dilakukan yakni menggunakan metode studi pustaka, observasi dan interview.

\subsection{Analisis Sistem}

Perancangan program adalah salah satu langkah yang penting sekali agar proses pembuatan aplikasi semakin terarah dan aplikasi yang dihasilkan bekerja dengan baik. Dengan menggunakan metode Nä̈ve Bayes Classifier apabila sistem menemukan suatu jenis fakta baru yang belum pernah dilakukan oleh siswa, maka pada prosesnya faka akan ditambahkan pada tabel fakta. Dari data fakta tersebut akan ditambahkan pada tabel aturan. Pada tabel aturan, nilai $\mathrm{P}(\mathrm{M} \mid \mathrm{X})$ akan dijumlahkan sesuai dengan data fakta yang diinputkan user.

\subsection{Perancangan Sistem Pakar}

Berikut ini adalah tahapan-tahapan yang dilakukan pada saat pengenmbangan sistem:

\section{Penilaian (assesment)}

Tahapan pertama pembuatan sistem pakar ini adalah melakukan pengkajian untuk permasalahan yang dihadapi oleh siswa serta pencarian solusinya pada proses bimbingan konseling.

2. Akusisi pengetahuan

Untuk mendapatkan pengetahuan dalam mengidentifikasi permasalahan siswa dilakukan dengan cara studi pustaka pada dokumen-dokumen atau penelitian-penelitian terdahulu yang berkaitan dengan topik yang dipilih serta wawancara dengan pakar

3. Desain

Pada tahapan ini yang dilakukan adalah membuat tabel aturan, diagram pelacakan forward chaining, kamus data, DAD, basis data yaitu ERD. Selain dari yang disebutkan diatas, antarmuka sistem juga sangat perlu dalam penelitian ini, karena antarmuka sistem nantinya akan digunakan untuk menginput, memproses serta menghasilkan solusi pada saat sistem pakar ini digunakan.

4. Implementasi

Dalam pembuatan aplikasi sistem pakar ini mengunakan bahasa pemrograman PHP, sedangkan pembuatan basis data menggunakan $M y S Q L$.

5. Pengujian

Tahap pengujian ini melalui dua tahap pengujian sistem yaitu dengan ussability test dan user acceptance test.

6. Dokumentasi

Dokumentasi dibutuhkan untuk menjelaskan tentang bagaimana mengoperasikan sistem dan menyediakan tutorial dalam mengoperasikan fitur dari sistem.

\section{Hasil dan Pembahasan}

\subsection{Analisis Kebutuhan Sistem}

Analisis kebutuhan sistem yang dibutuhkan meliputi:

1. Data masukan (input)

Data masukan yang diperlukan berupa data fakta yang nantinya akan digunakan untuk menampilkan data permasalahan dan data solusi atau rekomendasi.

2. Data keluaran (output)

Data keluaran yang akan ditampilkan pada sistem adalah berupa data solusi atau rekomendasi untuk suatu fakta yang dilakukan oleh siswa-siswi. 


\subsection{Kebutuhan Data}

Melalui metode-metode pengumpulan data yang digunakan, maka diperoleh data sebagai berikut:

1. Jumlah siswa yang pernah mengikuti proses konseling.

2. Fakta Bimbingan Konseling

3. Masalah Bimbingan Konseling

4. Nilai ambang dari fakta dan masalah

5. Rekomendasi dari Guru BK

\subsection{Alur Keputusan Sistem Pakar Bimbingan Konseling}

Pada alur keputusan ini, data yang telah di-input user akan diproses berdasarkan fakta yang dimasukan dan menghasilkan masalah, rekomendasi dan nilai kepastian. Pada gambar 2 merupakan alur keputusan.

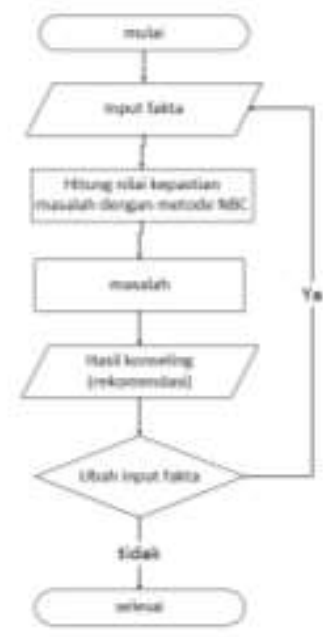

Gambar 1 . Alur keputusan sistem pakar bimbingan konseling

\subsection{Perancangan Sistem}

1. Diagram Alir Data

a. DAD level 1 sistem pakar konseling
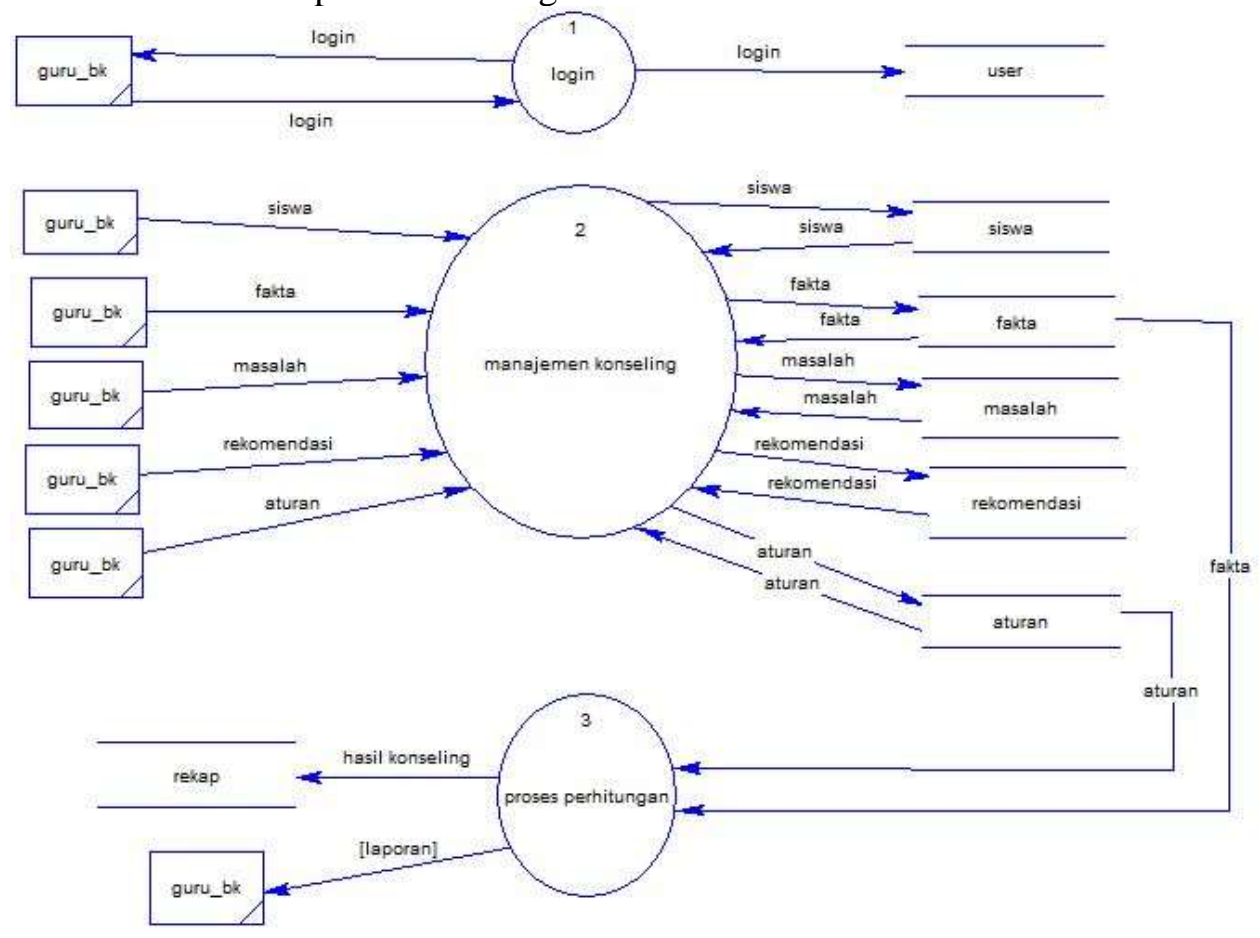
Gambar 2. DAD level 1 sistem pakar konseling

b. DAD level 1 Proses manajemen konseling

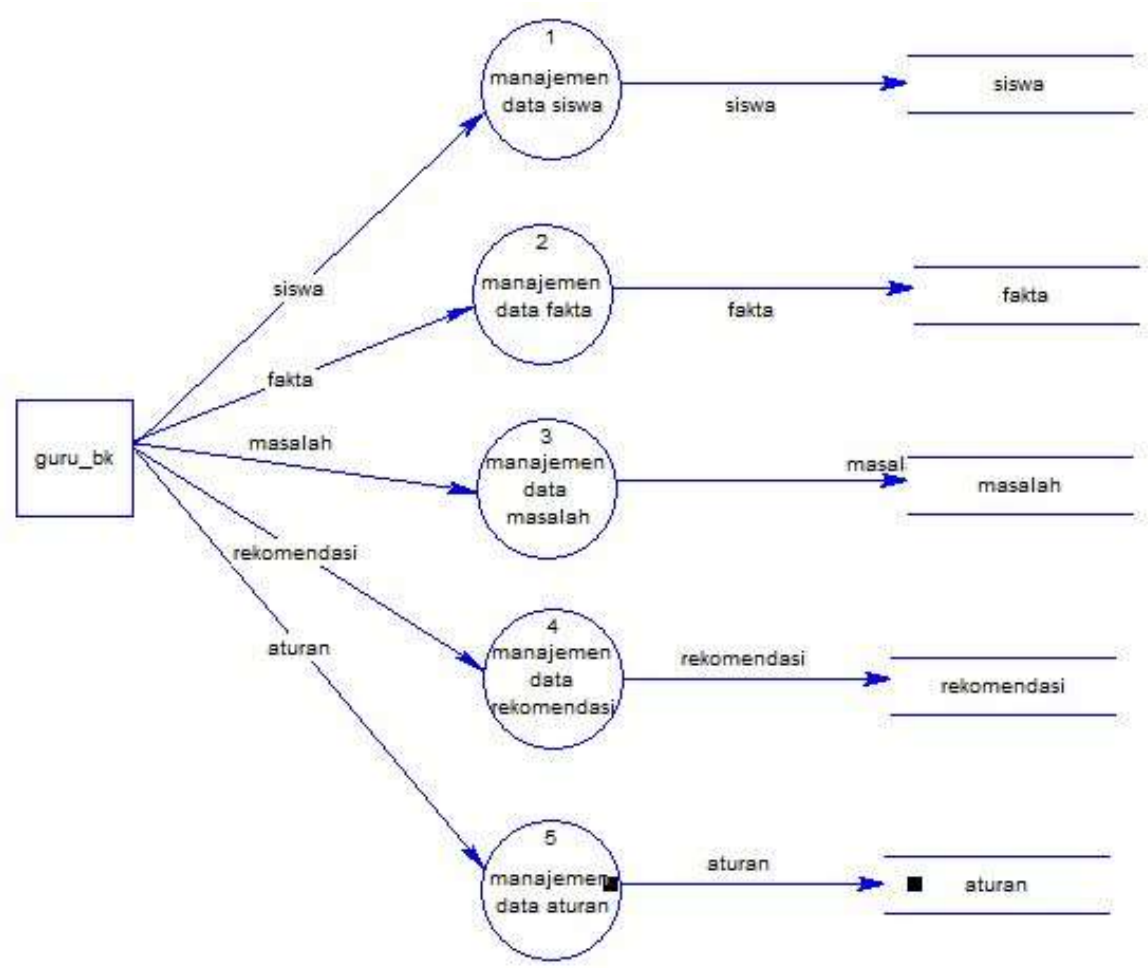

Gambar 3. DAD level 1 Proses manajemen konseling

\subsection{Manajemen Manajemen Data}

1. Entity Relationship Diagram (ERD)

Desain Entity Relationship Diagram (ERD) adalah sarana untuk menggambarkan hubungan antar data didalam sebuah system.

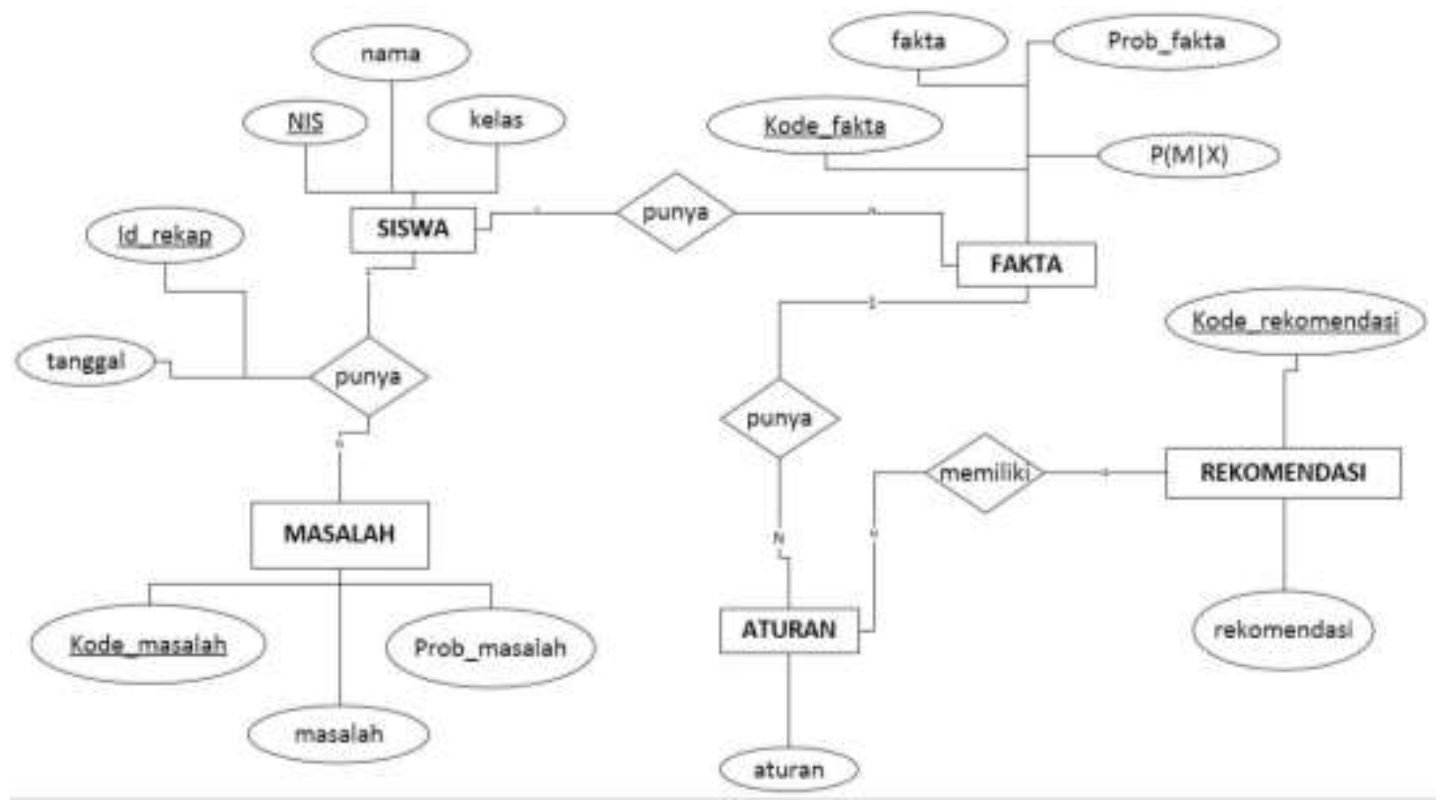

Gambar 4. ERD (Entity Relationships Diagram)

2. Mapping Table 
Mapping table digunakan untuk menggambarkan hubungan antar tabel entitas.

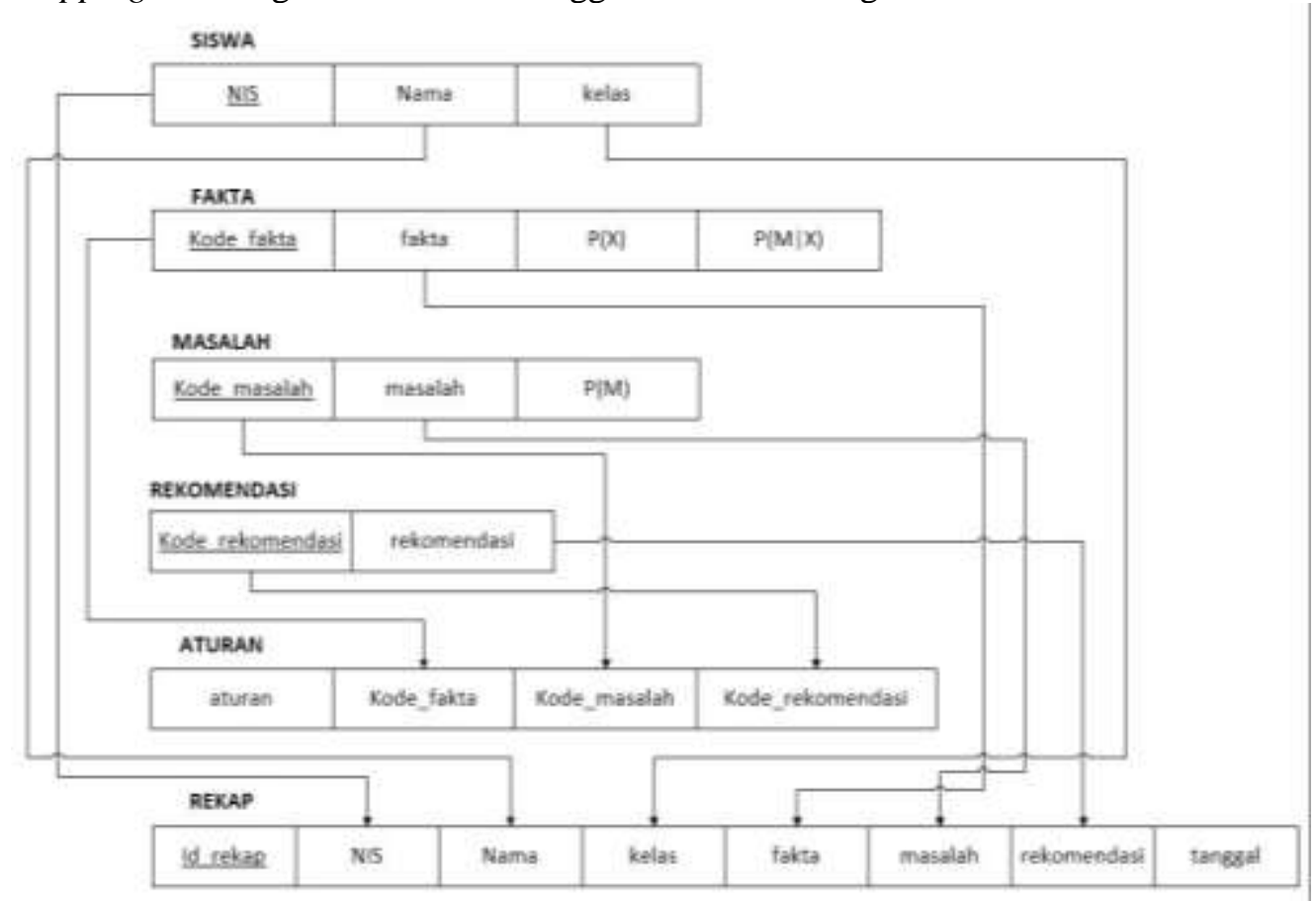

Gambar 5. Mapping Table

\subsection{Implementasi}

Pada aplikasi sistem pakar bimbingan konseling ini, pakar adalah sebagai admin yang dapat menambah, mengubah dan menghapus data. Sebelum menggunakan aplikasi ini, pakar harus terlebih dahulu untuk login dengan menggunakan username dan password yang sudah terdaftar. Setelah pakar melakukan login, pakar dapat menggunakan aplikasi sistem pakar sebagai wadah konseling dengan menekan button konseling berdasarkan nama dan NIS siswa yang akan melakukan konseling. Setelah menekan button konseling, pakar diminta untuk memilih fakta berdasarkan kasus dari siswa tersebut. Dari input-an fakta itu akan menghasilkan masalah, rekomendasi serta nilai kepastiannya. Selain sebagai wadah konsultasi, aplikasi ini juga nanti akan merekap semua data siswa yang pernah melakukan konseling.

\section{Form login}

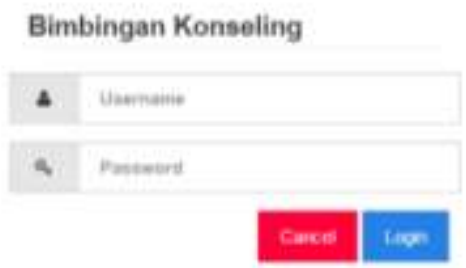

Gambar 6. Form login

\section{Menu Konsultasi Bimbingan Konseling}




\section{BIMBINGAN KONSELING}

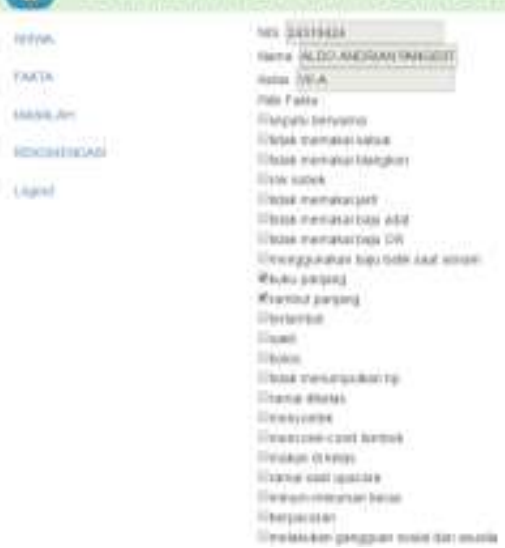

Gambar 7. tampilan pemilihan fakta.

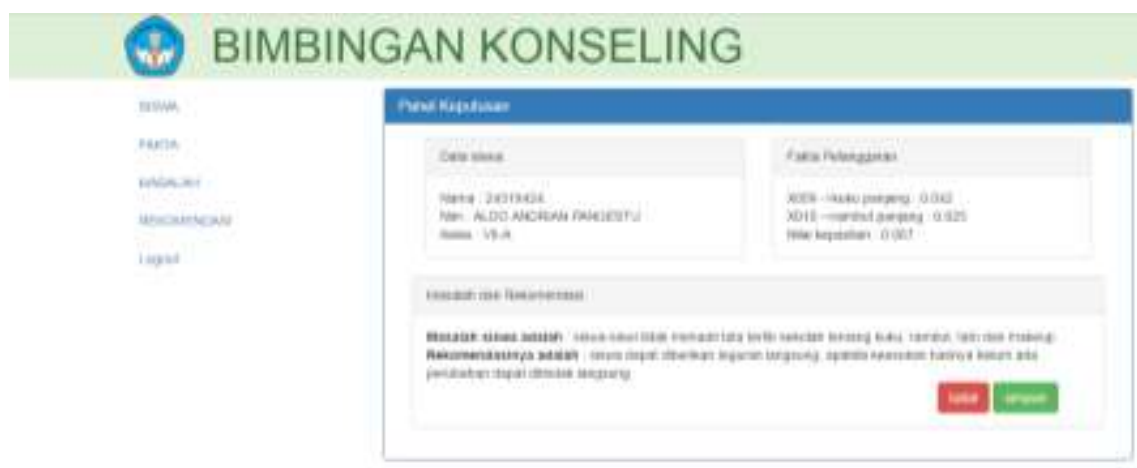

Gambar 8. tampilan hasil konseling.

\section{(9) BIMBINGAN KONSELING}

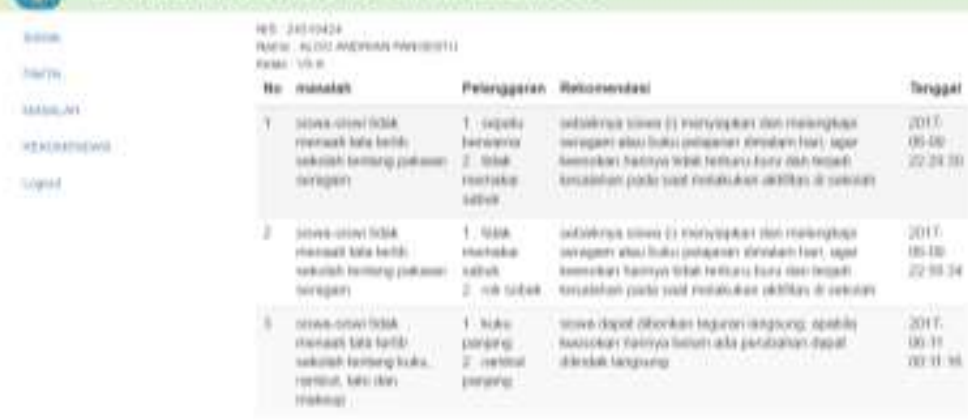

Gambar 9. rekapan konseling siswa.

\section{Kesimpulan}

\subsection{Kesimpulan}

Berdasarkan hasil penelitian dan pembahasan, maka dapat disimpulkan hal-hal sebagai berikut: 
1. Dari penelitan dihasilkan sebuah perangkat lunak baru tentang sistem pakar sebagai pendukung pengambilan keputusan masalah berdasarkan fakta-fakta yang terjadi pada sekolah. Dari fakta-fakta tersebut dapat mengahasilkan suatu keputusan masalah dan diakhir dengan solusi atau rekomendasi

2. Sistem mampu mendokumentasi serta menyimpan tentang representasi pengetahuan dari seorang pakar.

3. Sistem mampu memberikan diagnosa permasalahan, yaitu dari setiap fakta-fakta yang diinputkan oleh user akan diproses dan menghasilkan diagnosa permasalahan.

4. Sistem mampu merekap semua data siswa-siswi yang pernah melakukan proses konseling.

\subsection{Saran}

Saran-saran yang dapat disampaikan untuk pengembangan aplikasi ini, antara lain:

1. Sistem yang dibangun harus ditambah basis pengetahuannya melalui riset ataupun kerjasama dengan bidang keilmuan lain yang juga concern terhadap perkembangan permasalahan konseling siswa.

2. Penerapan metode Naive Bayes Classifier $(N B C)$ ini juga diharapkan dapat diterapkan pada studi kasus yang berbeda.

\section{DAFTAR PUSTAKA}

Jananto, Arif. 2013. Algoritma Naive Bayes untuk Mencari Perkiraan Waktu Studi Mahasiswa. Jurnal Teknologi Informasi DINAMIK. Universitas Stikubank.

Kusumadewi, Sri. 2003. Artificial Intelligence (Teknik dan Aplikasiya). Graha Ilmu, Jogjakarta

Nurhadryani Yani, dkk. 2013. Pengujian usability meningkatkan antarmuka aplikasi mobile. Jurnal Ilmu Komputer Agri-Informatika.

Ridwan Mujib, dkk. 2013. Penerapan Data Mining Untuk Evaluasi Kinerja Akademik Mahasiswa Menggunakan Algoritma Naïve Bayes Classifier. Jurnal EECCIS. 